\title{
Influence de la teneur en composants pariétaux (NDF) des ensilages d'herbe sur le comportement alimentaire et mérycique des ovins et des bovins
}

\author{
JM Embrechts, AG Deswysen \\ Université catholique de Louvain, faculté des sciences agronomiques, unité de génétique, \\ place Croix-du-Sud, 2, 1348, Louvain-la-Neuve, Belgique
}

La valeur alimentaire des fourrages est souvent mesurée sur ovins puis transposée aux bovins. L'objectif du présent travail est d'étudier de manière comparée entre ovins et bovins les variations de niveau d'ingestion volontaire et de comportement masticatoire en fonction de la teneur en NDF des ensilages d'herbe offerts à volonté aux animaux.

Les données de 19 études de comportement alimentaire d'animaux recevant ad libitum des ensilages d'herbe à brins courts constituent la base de ce travail. Onze expériences ont été réalisées sur moutons mâles castrés, de race Texel, âgés de 7-8 mois et 8 expériences sur génisses de race Pie-Noire, âgées de 16-29 mois ( 6 animaux par expérience). Aucun ensilage n'a été donné en commun aux ovins et aux bovins.

Chez les ovins comme chez les bovins, l'ingestion volontaire journalière de matière sèche (IVMS) diminue linéairement avec l'augmentation de la teneur en NDF des ensilages distribués (ovins : $r=-0,88 ; P<0,001$, et bovins : $r=-0,74 ; P<0,05)$. Pour des teneurs semblables en NDF, le niveau d'IVMS des ovins est inférieur à celui des bovins $\left(51,7\right.$ contre $86,3 \mathrm{~g} \mathrm{MS} / \mathrm{kg} \mathrm{P}^{0.75} / \mathrm{j}$; $P<0,001)$. En outre, la diminution d'IVMS concomitante à l'augmentation de la teneur en NDF de l'ensilage semble être plus importante chez les ovins que chez les bovins $(P=0,18)$ et est associée à une modification du comportement alimentaire et mérycique. Ainsi, les durées unitaires d'in- gestion et de rumination (DUI et DUR, en $\mathrm{min} / \mathrm{g} \mathrm{MS} / \mathrm{kg} \mathrm{P}^{0.75}$ ) augmentent linéairement avec l'augmentation de la teneur en NDF de l'ensilage (ovins, respectivement : $r=+0,86 ; P<0,001$ et $r=+0,93 ; P<0,001$, et bovins, respectivement : $r=+0,74 ; P<0,05$ et $r=+0,79 ; P<0,01)$. Cette augmentation de DUI et DUR concomitante à l'augmentation de la teneur en NDF de l'ensilage est plus importante chez les ovins que chez les bovins (respectivement, $P=0,07$ et $P<0,001$ ).

La quantité d'NDF ingérée quotidiennement (IVNDF) semble constante chez les ovins $\left(24,9 \mathrm{~g} \mathrm{NDF} / \mathrm{kg} P^{0,75} / \mathrm{j}\right)$ alors que, chez les bovins, elle augmente linéairement avec l'augmentation de la teneur en NDF de l'ensilage $(r=+0,83$; $P<0,001$ ).

En conclusion et en accord avec les observations de Dulphy et al (1980) et Reid et al (1988), les relations entre la teneur en NDF des ensilages et le niveau d'IVMS et d'IVNDF ainsi que les DUI et DUR diffèrent selon l'espèce. En outre, ces résultats semblent corroborer l'idée que les ovins seraient plus sensibles à une régulation "physique" de l'appétit que les bovins.

Dulphy JP, Rémond $B$, Thériez $\mathrm{M}(1980)$ In : Digestive physiology and metabolism in ruminants (Thivend $P$, Ruckebusch $Y$, eds) MTP Press Ltd, Lancaster, 103-122

Reid RL, Jung GA, Thayne WV (1988) J Anim Sci $66,1275-1291$ 